\section{Schweiker urges rethink on OMB cuts}

\section{Washington}

The Office of Management and Budget (OMB) is proposing broad cuts in healthrelated programmes for the budget for fiscal year 1984. The National Institutes of Health (NIH) and virtually every public health agency would be affected.

The proposal is contained in OMB's preliminary draft of the President's 1984 budget, which is supposed to be secret until the final budget is published in January. Confidential documents detailing OMB's plans for the health programme, together with a strong protest by Health and Human Services Secretary Richard Schweiker, are now, however, to hand.

According to the documents, OMB wants to limit the NIH budget to $\$ 4,013$ million; after inflation, this represents a cut from the current level of $\$ 3,954$ million. The short-fall could be made up by "various 'grant-stretching' mechanisms", OMB suggests, such as reducing direct costs of grants by 4 per cent to 20 per cent, cost-sharing with grantees and limiting "excessive personnel compensation". NIH director James Wyngaarden is known to be concerned about the last of these; NIH are at present conducting their own study of the growing proportion of research money used for principal investigators' salaries.

OMB also wants to revive two old and controversial cost-cutting proposals. One is a reduction in the indirect, or overhead, costs that NIH pay universities receiving grants. These payments go for fixed operating costs, such as office space. NIH last spring provoked a storm of protest from the universities when they proposed cutting indirect cost reimbursement by 10 per cent. Congress has since attached language to the NIH appropriations bill forbidding any such cuts. The other proposal is that NIH should charge patients at their clinical centre for routine hospital costs.

Schweiker's appeal against the OMB plan asks for an additional \$229 million for $\mathrm{NIH}$, which would allow the institutes to maintain their present level of 5,000 grants and 10,000 traineeships. The OMB cuts would reduce this to 3,200 grants.

The other Public Health Service agencies appear to fare worse under the OMB plan. The Food and Drug Administration (FDA) would have its budget frozen at the 1983 level and in addition would be required to eliminate 240 full-time positions. The Center for Disease Control (CDC) would have to fire 760 of its 4,162 full-time employees and reduce its budget by nearly one-third, from $\$ 318$ million to $\$ 215$ million. The appeal argues that "unless these funds are restored, CDC would lack the capacity to deal with emerging health problems" and would have to "limit research on controlling the 10 leading work-related health problems". It also takes exception to OMB's assumption that FDA could raise $\$ 5$ million by charging industry for the cost of processing new drug applications; FDA has not yet determined if "user charges can be collected without compromising the mission of the agency", the appeal says.

Schweiker is asking that OMB should add $\$ 35$ million to the FDA budget and allow the agency to maintain its current staff level, and to limit the CDC cuts to $\$ 54$ million and 60 full-time positions.

Schweiker is also protesting against organizational changes that OMB included in its budget plan. The most drastic of these would diminish the role of the assistant secretary for health, Dr Edward Brandt, to that of a policy adviser. Brandt, who is considered a powerful advocate of health issues, has operating authority over all of the Public Health Service agencies, including NIH, FDA, CDC and the Alcohol, Drug Abuse and Mental Health Administration; in addition, health promotion and environmental health programmes and the National Centres for Health Statistics and for Health Services Research are run directly from his office. The OMB plan would parcel out these programmes to the various agencies and would eliminate Brandt's authority over the agencies. In effect, the Public Health
Service structure would be abolished; each of the agencies would report directly to Secretary Schweiker.

One White House source said "I think Schweiker will be successful in appealing these massive organizationl changes which destroy the Public Health Service". The disposition of OMB and the President towards his other appeals is unknown, although there is strong support for a real increase in NIH funding within the President's Office of Science and Technology Policy.

If OMB's proposed cuts do survive Schweiker's appeal, they still face what is likely to be strong opposition in Congress. "Congress would not be very enthused about any of them", said a staff member of the House Appropriations Committee. The support for health research in Congress was demonstrated earlier this year when Congress added $\$ 312$ million to the Administration's $\$ 3,642$ million request for $\mathrm{NIH}$

And a staff member of the House Energy and Commerce Committee, which oversees the Public Health Service, pointed out that the President's budget has tended to carry less weight in recent years owing to the increasing use of continuing resolutions to provide funding. This mechanism is invoked when the new fiscal year arrives and the agency-by-agency appropriations bills have not yet been passed. Continued spending authority is lumped into a single stop-gap bill which a President must sign, or the government ceases operations. This restricts the President's power to impose his version of the budget on Congress.

Stephen Budiansky

\title{
Archaeopteryx in hiding
}

Rumours abound in palaeontological circles in Germany that a new specimen of Archaeopteryx lithographica was found by a private collector some time last year. The new find, from the classic SolenhofenEichstätt area of Bavaria, is purportedly as good as or better than the two existing complete specimens, one of which is in the British Museum

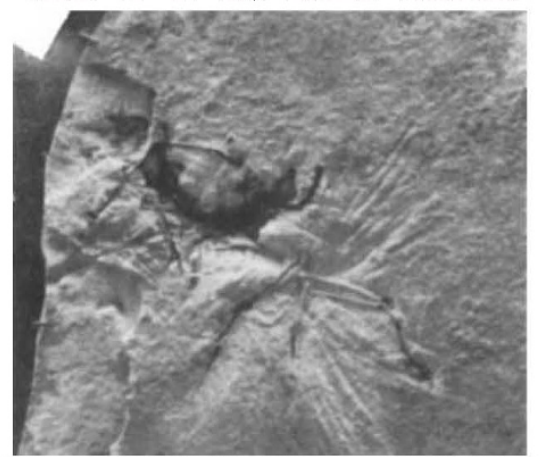

(Natural History) where it is undergoing a further round of extensive preparation.

Of the five known skeletons of Archaeopteryx (the sixth example is a single perfectly preserved feather) the “Maxberg exemplar” (see left) found in 1956 is the least known, as the owner is loth to allow specialists even a glimpse of it and only a preliminary description has ever been published.

Whereas the neighbouring state of Baden-Württemberg has legislation which prohibits the sale of finds of scientific importance without special museum authorization, in Bavaria, where no such legislation exists, it is a case of finders-keepers or sale to the highest bidder. And with prices in the hundreds of thousands of deutschmarks for Pterosaur speciments, what price an Archaeopteryx?

Mike Howgate 